\title{
Impedance Matching Simulation for Microstrip Antenna on Frequency 3.4-3.7 GHz Using Double Stub
}

\author{
Helfy Susilawati ${ }^{1 *}$, Ahmad Fauzi², Ahmad Hasyim ${ }^{3}$ \\ ${ }^{1}$ Universitas Garut \\ Jl. Jati No. 42B Tarogong Kab. Garut, Indonesia \\ ${ }^{2,3}$ Universitas Garut \\ Jl. Jati No. 42B Tarogong Kab. Garut, Indonesia \\ helfy.susilawati@uniga.ac.id ${ }^{1 *}$, ahmadfauzi627@gmail.com ${ }^{2}$, ahasyim76@yahoo.co.id ${ }^{3}$
}

\begin{abstract}
Impedance matching is an attempt to adjust the antenna impedance with the characteristic impedance of the transmission line. Impedance matching has functions to avoid reflected power from the antenna so that power cannot be received by the receiver. In this study, impedance matching was used double stub. The voltage standing wave ratio (VSWR) indicates how well the impedance matching is made. Simulation of this impedance matching will use to microstrip antenna on frequency $3.4-3.7$ GHz. CST Studio Suite is used to simulating the antenna microstrip with double stub. Based on the result, this research shows that VSWR and return loss in single and double rectangular microstrip antenna have a better value if use impedance matching than without using impedance matching.
\end{abstract}

Keywords: Impedance Matching, Simulation, Antenna, Microstrip, Double Stub.

\section{Introduction}

A microstrip patch antenna was the most popular, especially in microwave systems because of their attractive features [1]. Impedance matching has a function to match from source antenna to receiver antenna. Impedance matching is considered as an emerging line of research for the lower frequency bands of terahertz and microwave, due to its key role in enhancing the system performance [2]. An impedance matching network is a circuit typically comprised of inductors and capacitors that is used to match the impedance of the antenna to the RFFE over the required frequency range[3]. Using frequency in $3.4-3.7 \mathrm{GHz}$ because this frequency can use in $5 \mathrm{G}$ connectivity. 5G is the next generation of mobile and wireless technology, capable of providing ultrafast speeds, low latency and much greater reliability [4]. Basis of many initial 5G services is within the $3.3-3.8 \mathrm{GHz}$ [5]. 5G is currently in the development stage. 5G is expected to provide much more adaptive, flexible, and efficient radio access technologies compared to today's systems [6].

There are many studies on impedance matching to stabilize antennas, including research Jorge Simón and others. This study aims to match the impedance between the dipole lithographic antenna and the antenna microbolometers to ensure maximum power transfer [7]. Other research on antennas for $5 \mathrm{~g}$ networks has also been done, one of which is research Rashmitha $\mathrm{R}$ and others. In that research, a microstrip patch slot antenna for $5 \mathrm{G}$ and satellite communication has been designed. The simulation of the design has been carried out in Ansys HFSS v.15.0 simulation tool. The obtained results are found to be satisfying the requirements of the $5 \mathrm{G}$ communication antenna. The antenna works at a resonating frequency of $43.7 \mathrm{GHz}$ [8].

The difference between the research conducted and the other studies is that in the first study the different types of antennas were used. whereas in the second study, this study did not use

TELKA, Vol.6, No.2, November 2020, pp. 113 123

ISSN (e): 2540-9123

ISSN (p): 2502-1982 
impedance matching. This research also has shortcomings where the antenna design process is still using simulation.

\section{Research Method}

The design of impedance matching antenna used microstrip antenna with double stub and used rectangular and circle patch through several stages, they are determine the antenna specifications, choose the type of substrate, calculation of antenna dimensions, determine the input impedance and source impedance, calculation of stub dimensions, and antenna simulation. This simulation is designed by using CST software. Impedance matching in this research used microstrip antenna with double stub and used rectangular and circle patch.

A. Antenna specification

- Frekuensi $3.4-3.7 \mathrm{GHz}$

- $V S W R=1 \leq V S W R \leq 1.3$

- Return loss $\leq-10 \mathrm{~dB}$

B. Design of a rectangular patch microstrip antenna

Calculate characteristic impedance and load impedance and stub dimension. Calculate the characteristic impedance with equation (1):

$$
Z_{0}=\frac{\eta_{0}}{\sqrt{\varepsilon_{r e}}}\left\{\frac{W}{h}+1,393+0,667 \ln \left[\frac{W}{h}+1,444\right]\right\}^{-1}
$$

Calculate the load impedance with equation (2):

$$
Z_{L}=90 \frac{\left(\varepsilon_{r}^{2}\right)}{\left(\varepsilon_{r}-1\right)}\left(\frac{L}{\mathrm{~W}}\right)^{2}
$$

This is the dimension of a single rectangular patch microstrip antenna before using stub.

Table 1. Dimension of a single rectangular patch microstrip antenna before using stub.

\begin{tabular}{lll}
\hline Name & Wide & Length \\
\hline Patch & $33.55 \mathrm{~mm}$ & $27.71 \mathrm{~mm}$ \\
Supply $50 \Omega$ & $4.84 \mathrm{~mm}$ & $15.56 \mathrm{~mm}$ \\
Substrat & $43 \mathrm{~mm}$ & $48 \mathrm{~mm}$ \\
Ground plane & $43 \mathrm{~mm}$ & $48 \mathrm{~mm}$ \\
\hline
\end{tabular}

Table 1 shows the dimension of a single rectangular patch microstrip antenna before using stub. This dimension will be applied to microstrip antenna.

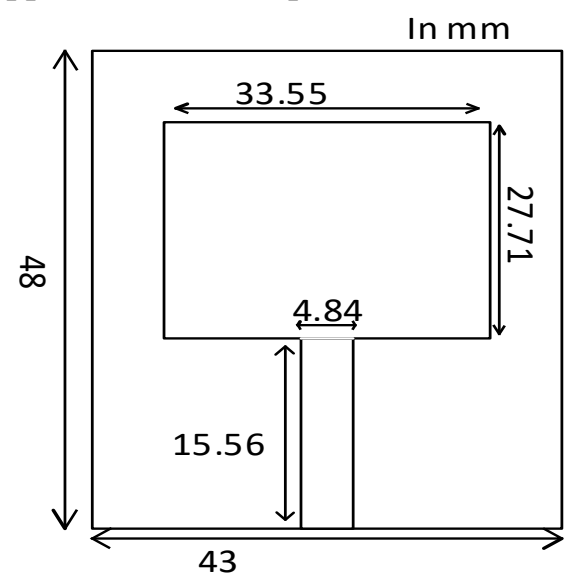

Figure 1. Design of a single rectangular patch microstrip antenna before using a stub impedance matching.

Figure 1 shows the design of single rectangular microstrip antenna without stub. To design antenna microstrip with stub, we have to calculate impedance characteristic and load impedance. Using the equation (1), we can find that impedance characteristic has a value $Z_{0}=50.46 \mathrm{ohm}$ and using aquation (2) we can find that load impedance has a value $\mathrm{Z}_{\mathrm{L}}=242 \mathrm{ohm}$. 
From the value of impedance characteristic and load impedance, range value between load and first stub is $5.07 \mathrm{~mm}$ and range between first stub and second stub is $3.16 \mathrm{~mm}$, with length for first stub is $5.23 \mathrm{~mm}$ dan length for second stub is $3.69 \mathrm{~mm}$. To get this value used Smith Chart Graphic.

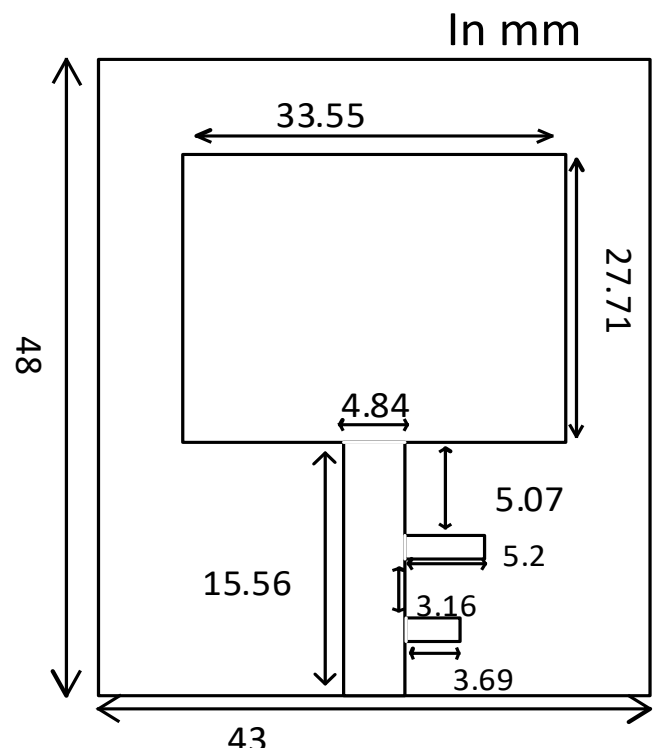

Figure 2. Design of a single rectangular patch microstrip antenna using stub impedance matching.

Figure 2 shows the single rectangular patch microstrip using stub. Next step is simulating the design using CST Studio Suite. The parameters generated are based on simulation is not fit to specification, so we have to optimizing the antenna. We can change the dimension of the stub, such as length stub and range between the stub to optimizing the antenna.

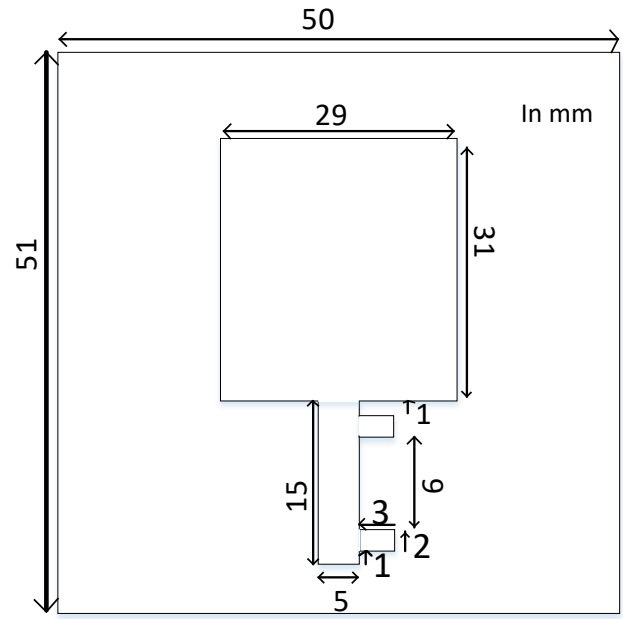

Figure 3. Optimization of the stub dimensions of the rectangular patch microstrip antenna impedance matching circuit.

Figure 3 shows the value to optimizing antenna. This value is obtained from try and error method in CST Studio Suite. After simulating the single rectangular microstrip antenna, we can analyze the value form the double rectangular microstrip antenna. The value for the double rectangular microstrip antenna using length and wide from the single rectangular microstrip antenna, we just have to add the range between the first patch and second patch. We can find a value between patches using the equation (3)

$$
d=\frac{C}{2 \times f_{0}} \text {. }
$$


We can find a value wide of ground plane using the equation (4)

$$
W_{g} \geq(6 \times h)+W \text {. }
$$

We can find a value length of ground plane using the equation (5)

$$
L_{g} \geq(6 \times h)+L \text {. }
$$

From the equation 3 , the value between patches is $42.25 \mathrm{~mm}$, the value wide of ground plane is $\mathrm{Wg} \geq 43 \mathrm{~mm}$, the value of length of ground plane is $\mathrm{Lg} \geq 37.16 \mathrm{~mm}$. because the dimension of ground pane has a smaller value than the dimension of patch, so we have to optimizing the value form the CST Studio Suite with add the value of wide and length of ground plane dimension.

Based on the CST Studio, we get the value for wide of ground plane is $140 \mathrm{~mm}$ and length of ground plane is $74 \mathrm{~mm}$. after we find the dimension of ground plane, we have to find the value of length and wide when using supply $100 \Omega$ and supply $50 \Omega$. Equation to find the value is:

$$
\begin{aligned}
& B=\frac{60 \pi^{2}}{Z_{0} \sqrt{\varepsilon_{r}}} \\
& W=\frac{2 h}{\pi}\left\{B-1-\ln (2 B-1)+\frac{\varepsilon_{r}-1}{2 \varepsilon_{r}}\left[\ln (B-1)+0.39-\frac{0.61}{\varepsilon_{r}}\right]\right\} \\
& \varepsilon_{r e f f}=\frac{\varepsilon_{r}+1}{2}+\frac{\varepsilon_{r}-1}{2}\left[1+12 \frac{h}{W}\right]^{\frac{-1}{2}} \\
& \lambda_{g}=\frac{C}{f_{0} \sqrt{\varepsilon_{r e f f}}} \\
& L_{f}=\frac{\lambda_{g}}{4}
\end{aligned}
$$

After we find the wide and length from the equation, we can determine the dimension of the ground plane. The dimension of ground plane using microstrip antenna using double rectangular patch is shown in the Table 2.

Table 2. Dimension of microstirp antenna using double rectangular patch without stub.

\begin{tabular}{lcc}
\hline \multicolumn{1}{c}{ Name } & Wide $(\mathrm{mm})$ & Length $(\mathrm{mm})$ \\
\hline patch & 33.55 & 27.71 \\
Spply $100 \Omega$ & 1.37 & 16.025 \\
Connector & 1.37 & 77.17 \\
Supply $50 \Omega$ & 4.84 & 15.56 \\
substrat & 140 & 74 \\
Ground plane & 140 & 74 \\
\hline
\end{tabular}

Table 2 shows the dimension of microstrip antenna using doble rectangular patch without using stub. This value will be applied to design of microstrip antenna using double rectangular patch.

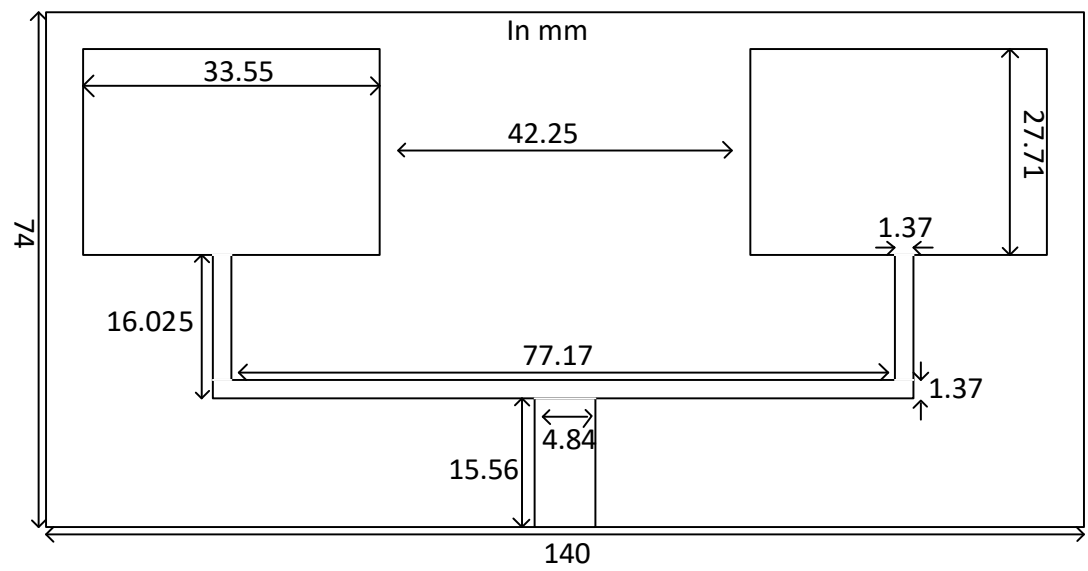

Figure 4. Design of a double rectangular patch microstrip antenna before using a stub impedance matching. 
Figure 4 shows the design of a double rectangular patch microstrip antenna before using a stub impedance matching. We can se that patch has a same value with using single rectangular patch. The parameters generated are based on simulation is not fit to specification, so we have to optimizing the antenna. We can change the dimension of the stub, such as length stub and range between the stub to optimizing the antenna.

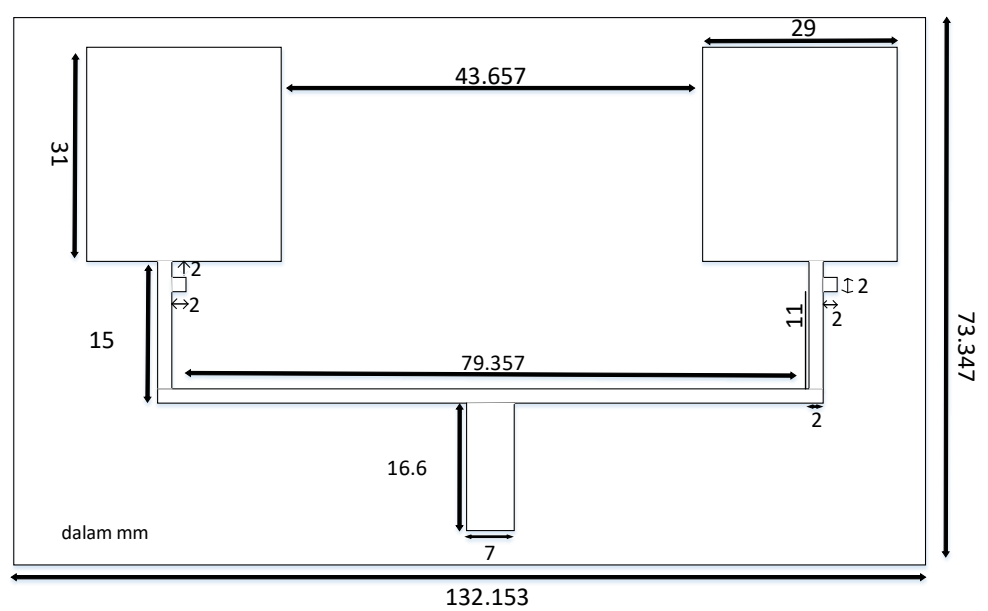

Figure 5. Design of a double rectangular patch microstrip antenna after using a stub impedance matching.

Figure 5 shows the design of a double rectangular patch microstrip antenna after using a stub impedance matching. The value of impedance matching has a same value with the value impedance matching in single rectangular patch microstrip antenna.

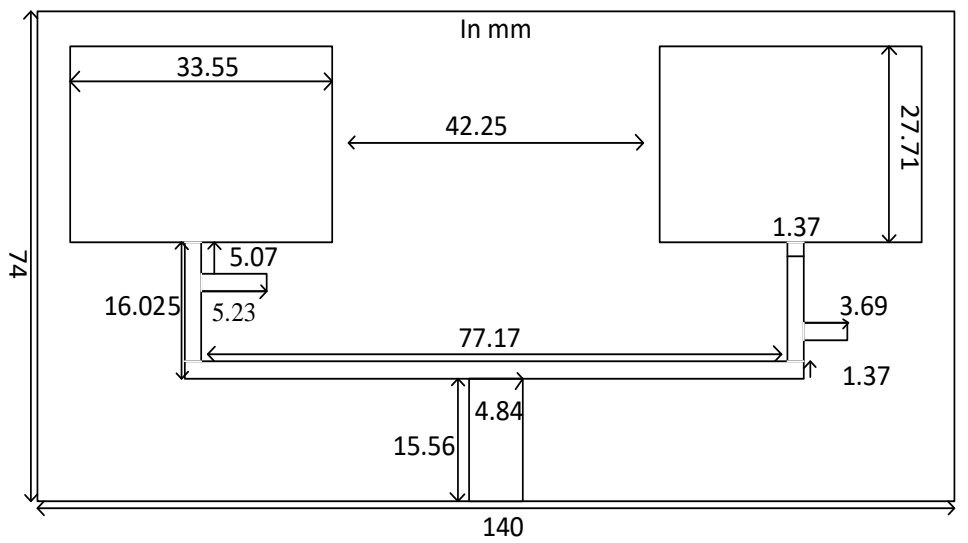

Figure 6. Optimization of a double rectangular patch microstrip antenna after using a stub impedance matching.

Figure 6 shows the value to optimizing antenna. This value is obtained from try and error method in CST Studio Suite.

\section{Results and Discussions}

\subsection{Single Rectangular Microstrip Antenna}

The basis and reference to see the work of an antenna impedance matching is by analyzing antenna parameters. In this study the antenna parameters analyzed are: return loss and VSWR. 


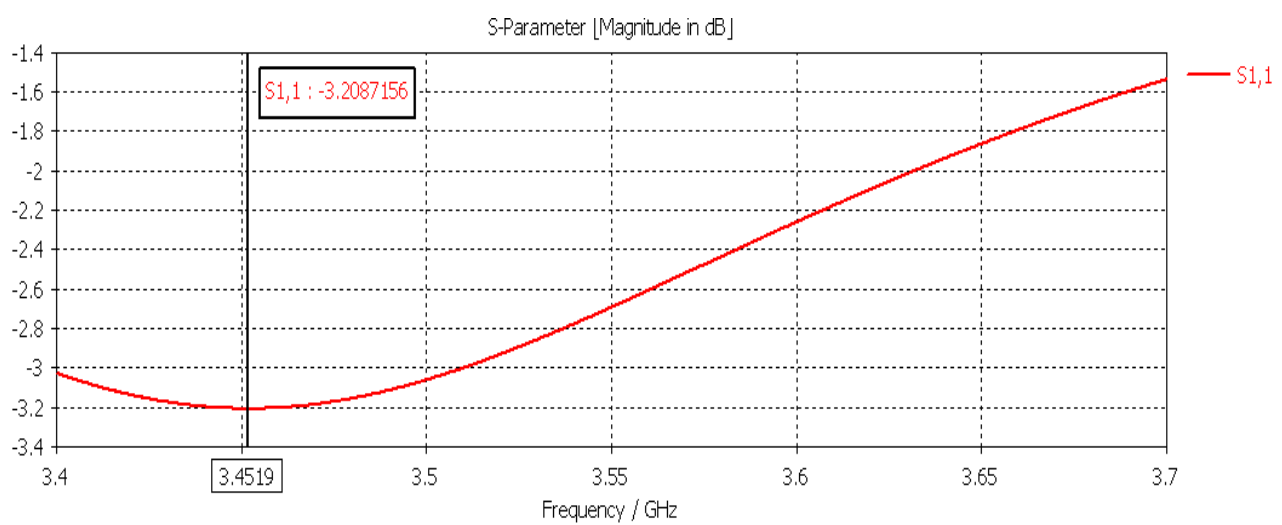

Figure 7. Return loss of a single rectangular microstrip antenna before using a stub impedance matching.

Figure 7 shows the return loss design of a single rectangular microstrip antenna before using a stub impedance matching. Based on figure 7 at $3.4519 \mathrm{GHz}$ frequency the return loss value is $3.2087156 \mathrm{~dB}$ which means it is still not in accordance with the specified antenna specifications. In addition, the value of $-3.2087156 \mathrm{~dB}$ is still not good because not all the power is emitted or there is still reflected power so that it will affect the VSWR value.

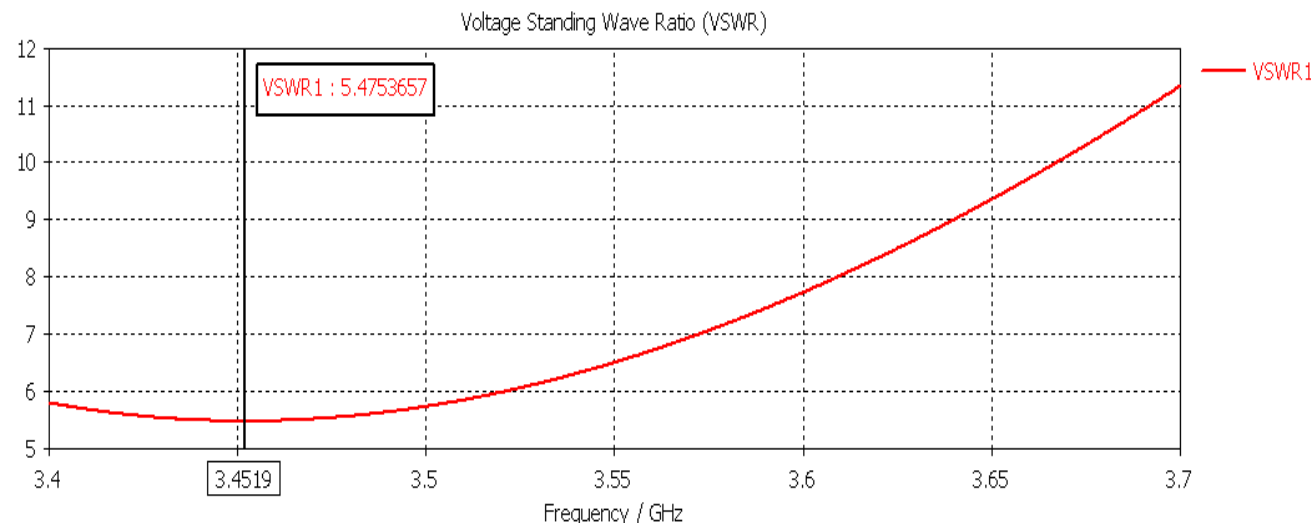

Figure 8. VSWR single rectangular microstrip antenna before using stub impedance matching.

Based on Figure 8, at 3.4519 GHz the VSWR value of the antenna is 5.4753657, this value is far from the specified antenna specifications which is close to 1 . From the two parameters above it can be said that the design of a single element rectangular patch microstrip antenna does not work well in the frequency range of $3.4-3.7 \mathrm{GHz}$.

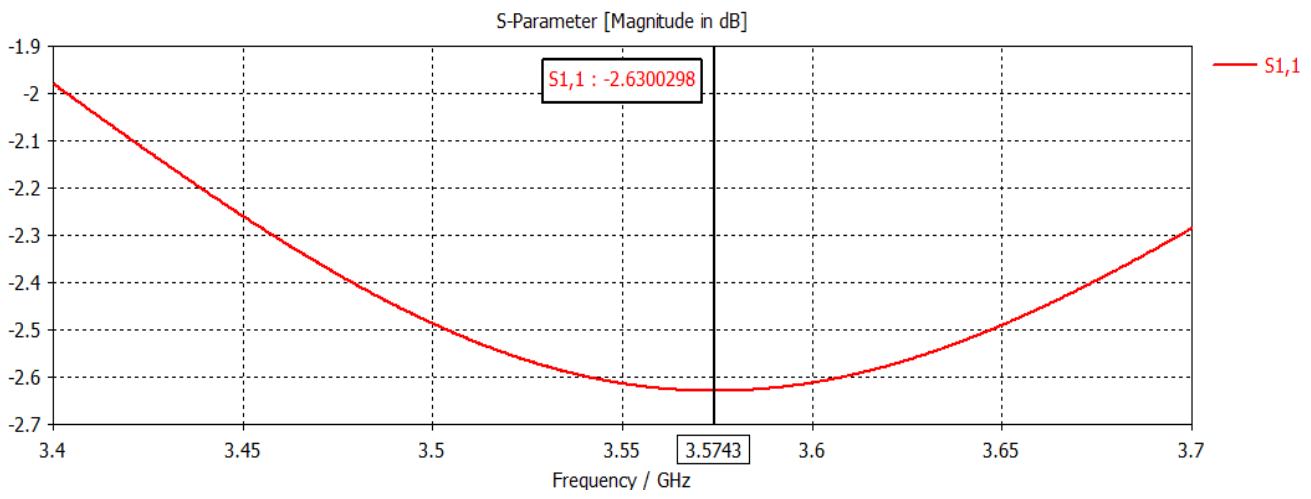

Figure 9. Return loss of a single rectangular microstrip antenna after using a stub impedance matching.

ISSN (e): 2540-9123

ISSN (p): 2502-1982 
From the figure 9 it can be seen that the frequency of $3.5743 \mathrm{GHz}$ return loss value is $2.6300298 \mathrm{~dB}$ after the stub has been pinned, the return loss value has gotten worse. From $3.2087156 \mathrm{~dB}$ to $-2.6300298 \mathrm{~dB}$ this value will certainly affect the VSWR value.

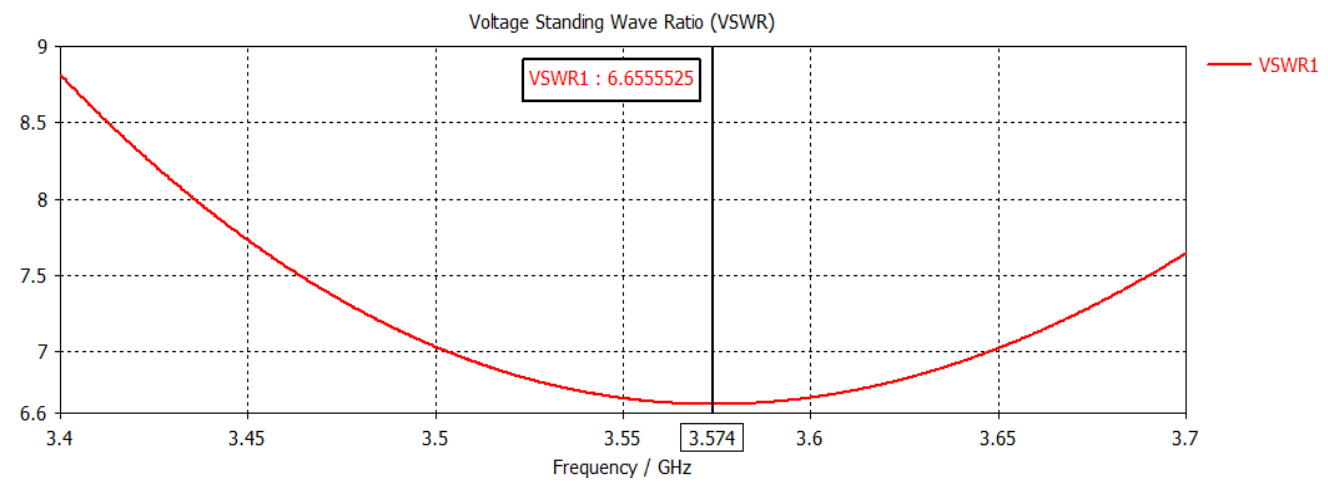

Figure. 10. VSWR single rectangular microstrip antenna after using a stub impedance adjustment.

From the figure 10 we get a VSWR value of 6.6555525 on a frequency of $3.574 \mathrm{GHz}$ which means that the value of VSWR becomes worse as well as the value of return loss. Thus the impedance matching circuit of a single rectangular patch microstrip antenna cannot work in the frequency range $3.4-3.7 \mathrm{GHz}$.

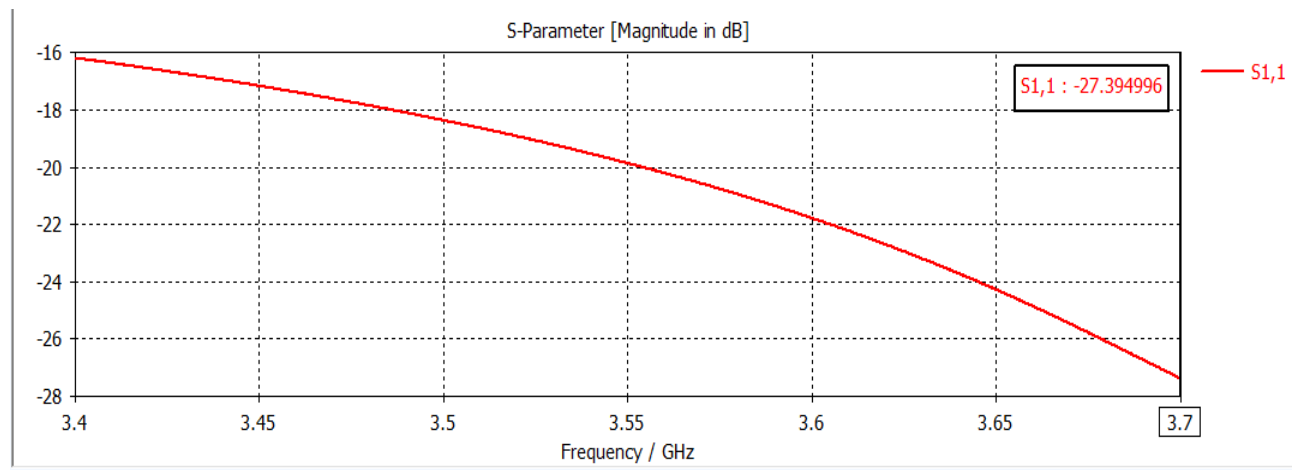

Figure 11. Return loss of the rectangular patch patch microstrip antenna impedance matching with optimization.

Based on figure 11, s-parameter is the smallest value of return loss, which is $-27.394966 \mathrm{~dB}$ at the frequency of $3.7 \mathrm{GHz}$. At frequency 3.4 the value of return loss is $-16.197588 \mathrm{~dB}$ and at the middle frequency of $3.55 \mathrm{GHz}$ the value of return loss is -19.874005 which means the antenna can work along the frequency of $3.4-3.7 \mathrm{GHz}$ because the return loss value is still included in the specified antenna specifications namely $\leq-10 \mathrm{~dB}$. By optimizing and embedding a double stub on the microstrip antenna the antenna performance will get better.

Figure 12 shows that the smallest VSWR value at the frequency of $3.7 \mathrm{GHz}$ is 1.0891711 The value of VSWR has increased compared to before doing optimization, because the closer to 1 , the VSWR value will be better, the value of VSWR is also strongly influenced by return loss. While for the middle frequency VSWR value is 1.2258358 and the highest VSWR value in this impedance adjustment circuit is at frequency 3.4 which is 1.3666529 , this means that the antenna impedance adjustment circuit after optimization can work well along the frequency range 3.4 $3.7 \mathrm{GHz}$. 


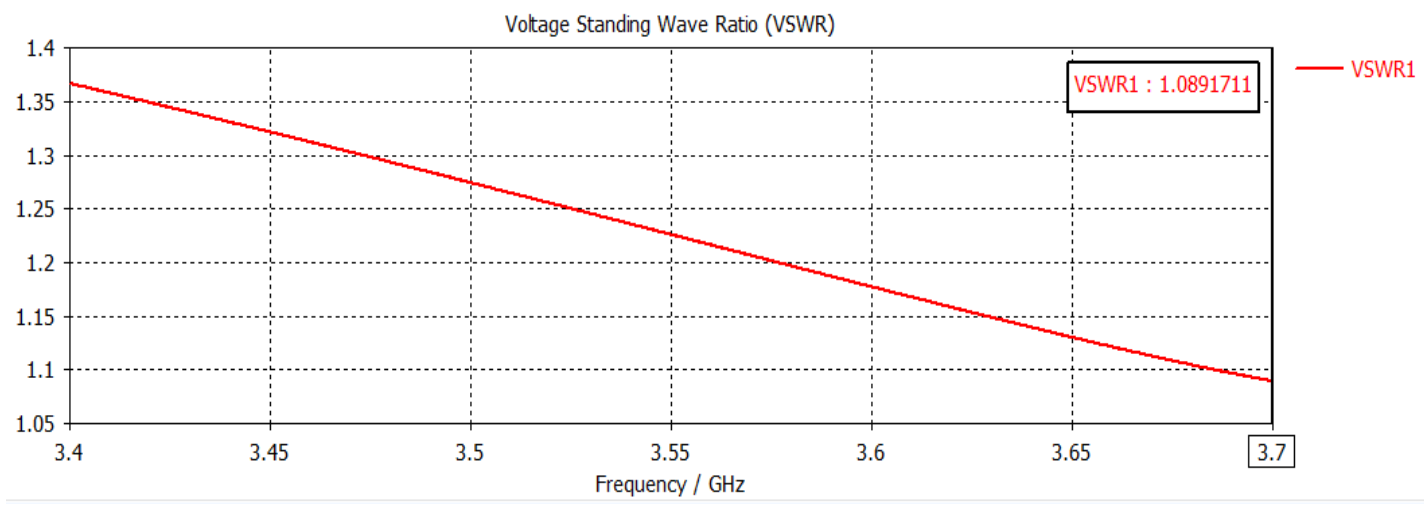

Figure 12. VSWR from the impedance matching circuit of rectangular patch microstrip antenna with optimization.

Table 3. Comparison between single rectangular microstrip antenna with and without optimization.

\begin{tabular}{crr} 
Single rectangular microstrip antenna & Return loss & VSWR \\
\hline Without optimization & $-2.6300298 \mathrm{~dB}$ & 6.6555525 \\
With optimization & $-27.394966 \mathrm{~dB}$ & 1.0891711 \\
\hline
\end{tabular}

From the Table 3, it can be seen that the design of a rectangular patch microstrip antenna impedance matching has poor antenna parameters, return loss and VSWR values do not meet the specified antenna parameters. After optimizing the return loss stub and the VSWR has a very good simulation result because the value is getting smaller, this means that the impedance adjustment circuit on the antenna can work well.

\subsection{Double Rectangular Microstrip Antenna}

Figure 13 shows the value of return loss at $3.4615 \mathrm{GHz}$ is $-11.743903 \mathrm{~dB}$. This value is included in the specified antenna specifications.

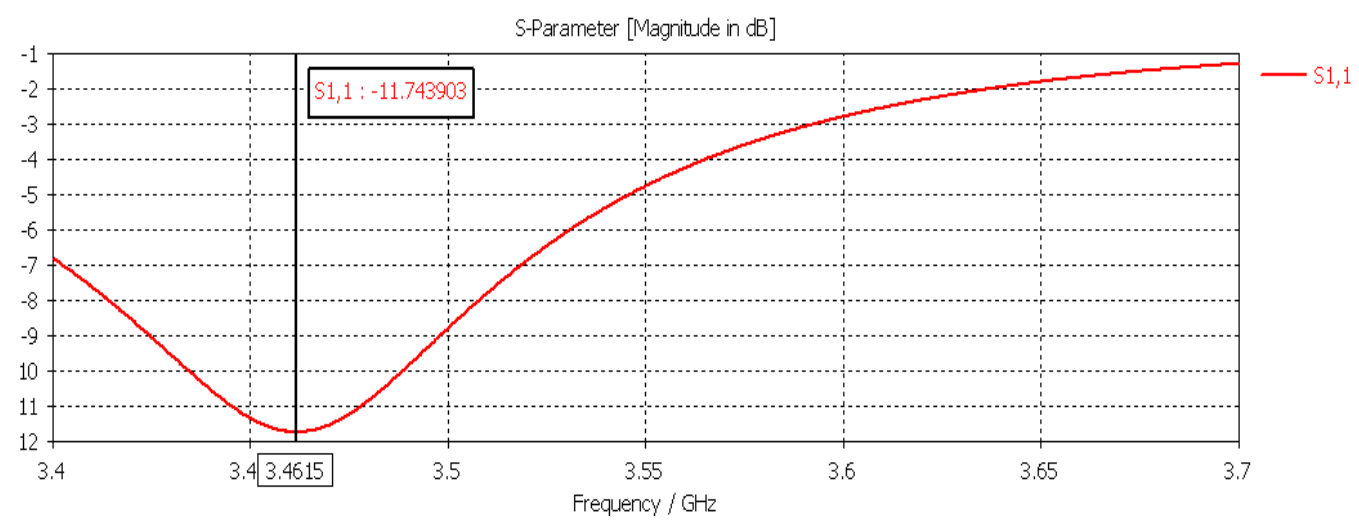

Figure 13. Return loss of double rectangular microstrip antenna before using stub impedance matching 


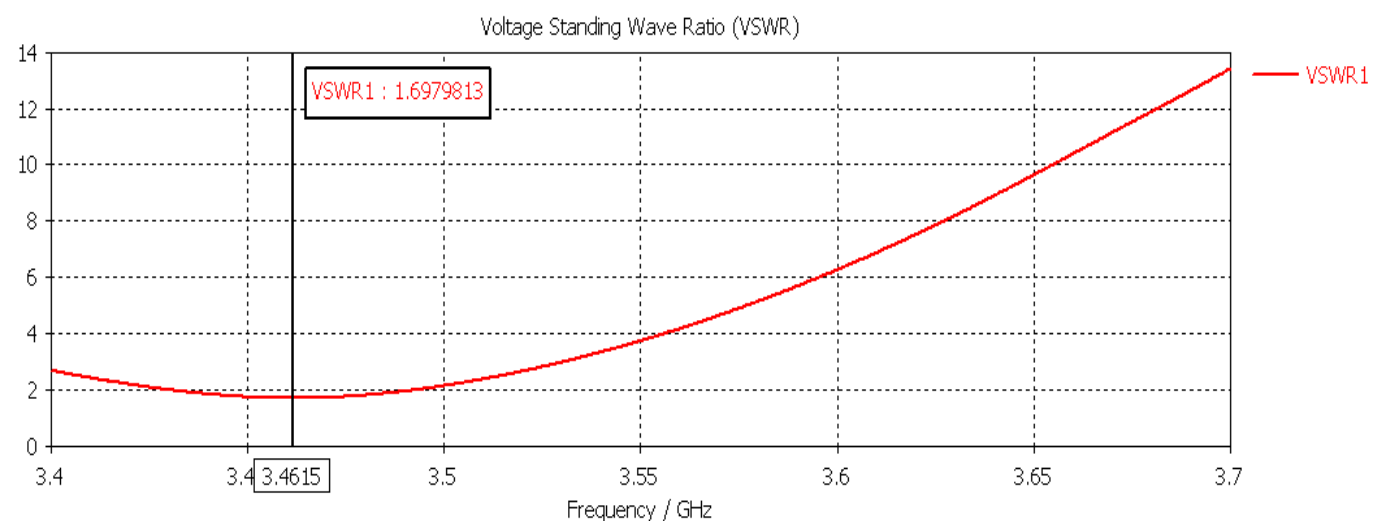

Figure 14. VSWR of double rectangular microstrip antenna before using stub impedance matching.

Based on figure 14, VSWR has a value 1.6979813, that is included in the specified antenna specification criteria so that it can be said that the antenna can work at a frequency of 3.4615.

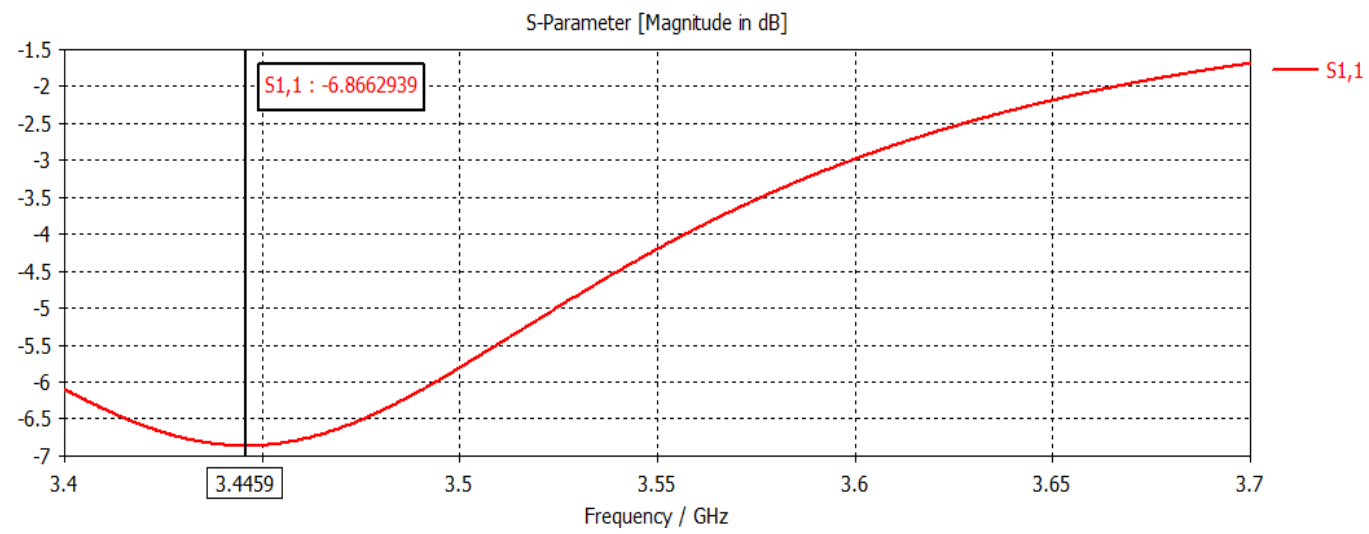

Figure 15. Return loss of double rectangular microstrip antenna after using stub impedance matching without optimization.

Figure 15 shows that the return loss value is $-6.8662939 \mathrm{~dB}$ at the frequency of $3,4459 \mathrm{GHz}$. The return loss value is not good because it does not match the specified antenna parameter specifications.

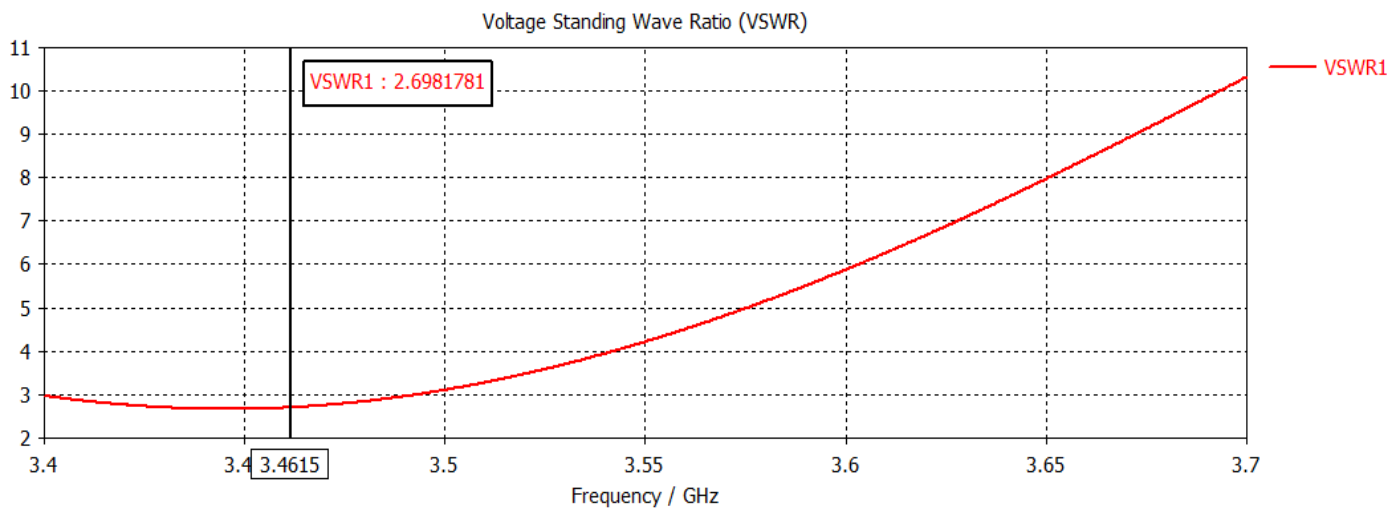

Figure 16. VSWR of double rectangular microstrip antenna after using stub impedance matching without optimization.

Based on figure 16, the VSWR value is 2.6981781 at $3.4615 \mathrm{GHz}$. This VSWR value is still not good enough and this impedance matching circuit cannot work in the $3.4-3.7 \mathrm{GHz}$ frequency range because the VSWR value is still far from the expected antenna parameters. 


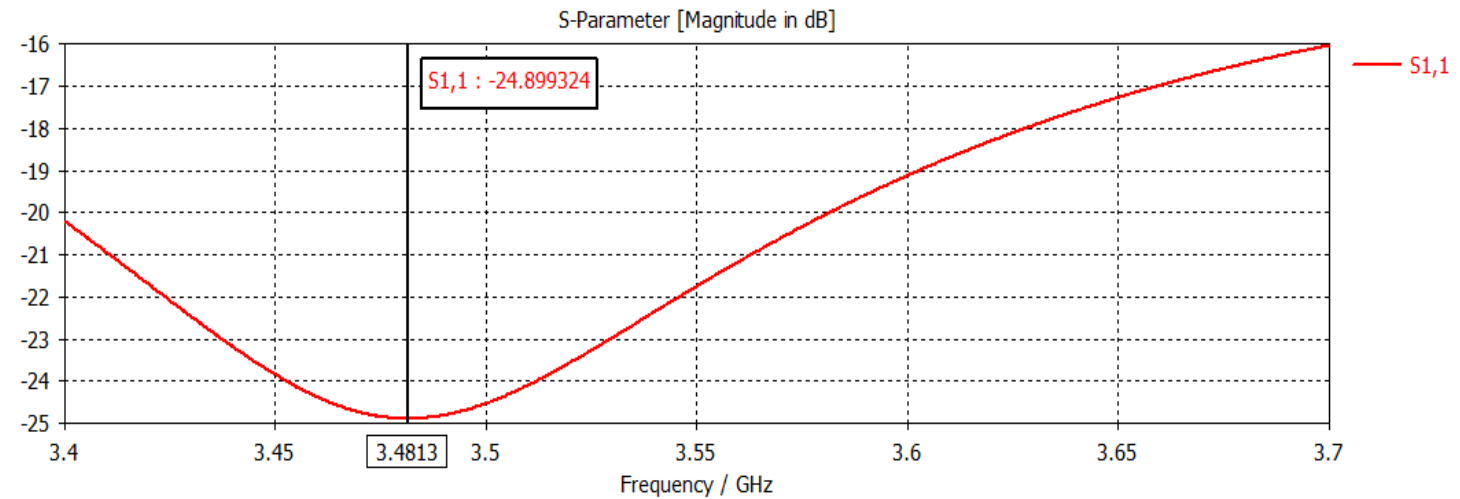

Figure 17. Return loss of double rectangular microstrip antenna after using stub impedance matching with optimization.

The smallest value of the S-parameter or return loss in the rectangular patch microstrip impedance adjustment circuit after optimization is $-24.899324 \mathrm{~dB}$ at the $3.4813 \mathrm{GHz}$ frequency, this value is smaller and entered into the specified antenna specifications that is $<-10 \mathrm{~dB}$. Figure 17 shows the highest point of return loss of $-16 \mathrm{~dB}$ at a frequency of $3.7 \mathrm{GHz}$ and is still smaller when compared with the specified antenna specifications. This means that the impedance matching can work in the frequency range $3.4-3.7 \mathrm{GHz}$.

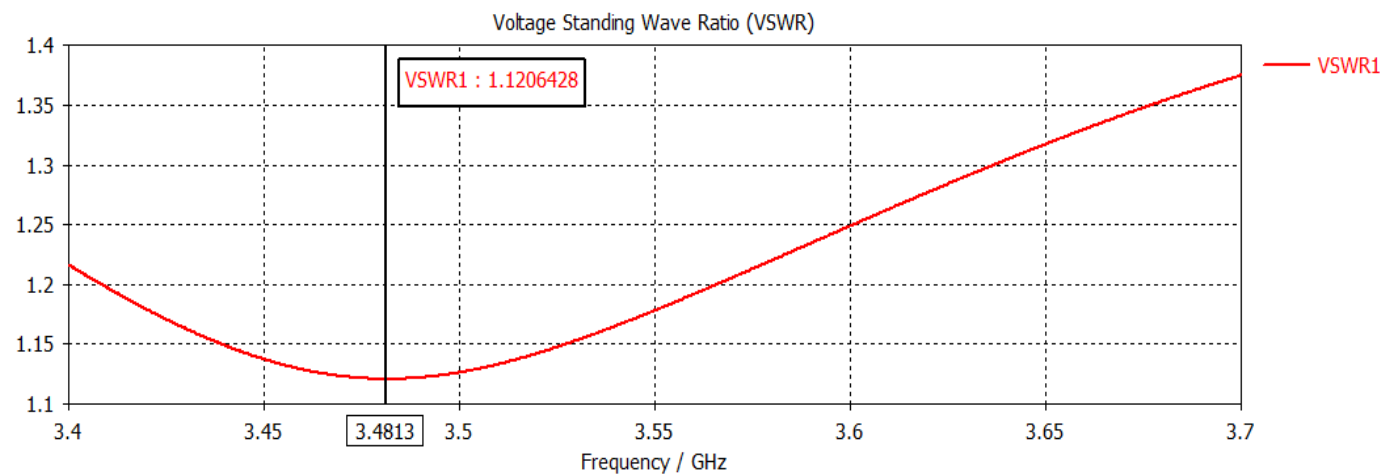

Figure 18. VSWR of double rectangular microstrip antenna after using stub impedance matching with optimization.

The simulation using impedance matching with optimization is resulting in the lowest VSWR value of 1.1206428 at the same frequency of $3.4813 \mathrm{GHz}$. This value is quite good because it is getting closer to 1 . The highest value of VSWR is 1.3844826 at the frequency of $3.7 \mathrm{GHz}$ and VSWR at the frequency of $3.4 \mathrm{GHz}$ at 1.2223564 . From the three VSWRs produced by this antenna can be said to work well on the frequency of $3.4-3.7 \mathrm{GHz}$ because the value of VSWR is not more than 1.3.

Table 4. Comparison between double rectangular microstrip antenna with and without optimization.

\begin{tabular}{ccc}
\hline $\begin{array}{c}\text { Double rectangular } \\
\text { microstrip antenna }\end{array}$ & Return loss & VSWR \\
\hline Without optimization & $-6.8662939 \mathrm{~dB}$ & 2.6981781 \\
With optimization & $-24.899324 \mathrm{~dB}$ & 1.1206428 \\
\hline
\end{tabular}

Table 4 shows the comparison return loss and VSWR between antenna without optimization and antenna without optimization. This research has not designed the antenna, but still uses simulation. 


\section{Conclussion}

Impedance matching utilization in rectangular microstrip antenna results a different value, for the single stub the lowest VSWR value is 1.0891711 at the frequency of $3.7 \mathrm{GHz}$ while the highest VSWR value is 1.3666529 at the $3.4 \mathrm{GHz}$ frequency, and the double stub is the lowest VSWR value at 1.1206428 at the $3.48 \mathrm{GHz}$ frequency then the highest value is 1.3666529 at the $3.4 \mathrm{GHz}$ frequency, and the double stub is the lowest VSWR value at 1.1206428 at the $3.48 \mathrm{GHz}$ frequency then the highest value is 1.3844826 is on the $3.7 \mathrm{GHz}$ frequency, visible VSWR values of both patch types $<1.3$. Return loss for single stub is $-27.394966 \mathrm{~dB}$ at $3.7 \mathrm{GHz}$ frequency, and for double stub of $-24.899324 \mathrm{~dB}$ at $3.4 \mathrm{~dB}$ frequency, visible loss value $<-10 \mathrm{~dB}$. VSWR and return loss in single and double rectangular microstrip antenna have a value better if use impedance matching than without using impedance matching.

\section{Acknowledgement}

I would like to thank to Institution that support us to make this research and publish the research. Thanks to people that is I quote they research as references.

\section{Referensi}

[1] S. N. S. Mahmud, M. A. Jusoh, S. E. Jasim, A. H. Zamani, and M. H. Abdullah, "Design, simulation and analysis a microstrip antenna using PU-EFB substrate," 2018, doi: 10.1088/1757-899X/342/1/012021.

[2] K. Bhattacharyya, S. Goswami, K. Sarmah, and S. Baruah, "A linear-scaling technique for designing a THz antenna from a GHz microstrip antenna or slot antenna," Optik (Stuttg)., 2019, doi: 10.1016/j.ijleo.2019.163331.

[3] B. A. Kuchikulla, S. M. Manager, and M. Products, "Applying Impedance Tuning to Maximize Antenna Performance in 5G Phones (Smith Chart Regions)," no. January 2020, pp. 1-22.

[4] S. M. Asif, M. R. Anbiyaei, K. L. Ford, T. O’Farrell, and R. J. Langley, "Low-Profile Independently-and Concurrently-Tunable Quad-Band Antenna for Single Chain Sub-6GHz 5G New Radio Applications," IEEE Access, vol. 7, pp. 183770-183782, 2019, doi: 10.1109/ACCESS.2019.2960096.

[5] Huawei, "5G Spectrum - Public Policy Position," 2016.

[6] J. Nadal, C. Abdel Nour, and A. Baghdadi, "Flexible and efficient hardware platform and architectures for waveform design and proof-of-concept in the context of 5G," AEU - Int. J. Electron. Commun., 2018, doi: 10.1016/j.aeue.2018.09.030.

[7] J. Simón, E. S. Kolosovas-Machuca, G. Vera-Reveles, E. Briones, J. Flores-Troncoso, and F. J. González, "Enhancement of antenna-coupled microbolometers response by impedance matching," J. Appl. Res. Technol., vol. 13, no. 5, pp. 523-525, 2015, doi: 10.1016/j.jart.2015.10.005.

[8] R. Rashmitha, N. Niran, A. A. Jugale, and M. R. Ahmed, "Microstrip Patch Antenna Design for Fixed Mobile and Satellite 5G Communications," Procedia Comput. Sci., vol. 171, no. 2019, pp. 2073-2079, 2020, doi: 10.1016/j.procs.2020.04.223. 